\title{
Political Participation of Mobile Citizens and the Size of the Welfare State
}

\author{
Oliver Lorz* and Stanislav Nastassine**
}

\begin{abstract}
This paper deals with the implications of personal mobility for political participation of citizens and for the resulting size of the welfare state. We show that mobility of citizens may influence the individual decision to participate in the political process and thereby may change policy outcomes. If citizens who prefer a larger public sector are relatively immobile, the size of the welfare state may increase with mobility. (JEL D72, J61)
\end{abstract}

\section{Introduction}

Mobility is often seen as a reason for a decline in the size of the welfare state as it makes it more difficult for governments to redistribute incomes between individuals. ${ }^{1}$ Citizens who expect positive net social transfers have an incentive to move to a jurisdiction with a comparatively generous welfare system whereas the opposite holds for those who are net contributors to social welfare programs. Under these circumstances, interjurisdictional competition may induce governments to cut down on social welfare programs - a "race to the bottom" results.

Our paper considers an alternative mechanism by which interjurisdictional mobility can influence the size of the welfare state: mobility may reduce participation of citizens in the political decision-making process since mobile citizens may anticipate a possible relocation to another jurisdiction in the foreseeable future. Mobility then causes a participation bias towards less mobile citizens. This participation effect may work against the interjurisdictional competition effect described above if highly mobile citizens prefer a leaner welfare state than the less mobile ones.

* RWTH Aachen, University, e-mail:lorz@rwth-aachen.de.

** University of Konstanz, email: stanislav.nastassine@uni-konstanz.de.

We would like to thank Heinrich W. Ursprung for valuable discussions and suggestions. We are also grateful to Silke Uebelmesser, two anonymous referees and participants at the CESifo Economic Studies Conference "Migration and the Welfare State" for their helpful comments. All remaining errors are our own.

1 See Oates (1972). Formal models in this vein are provided, for example, by Brown and Oates (1987), Wildasin (1991) or Sinn (1997). For an overview see Brueckner (2000), Cremer et al. (1996) or Cremer and Pestieau (2003).

(C) Ifo Institute for Economic Research, Munich, 2004 
In this paper we take a closer look at the potential implications of this participation effect for the size of the welfare state. We consider citizens who differ with respect to their education level and therefore with respect to their expected lifetime income. We assume that better educated citizens with a higher expected permanent income prefer a smaller size of the welfare state. ${ }^{2}$ In addition, the better educated are also generally more mobile than others. If one combines these two elements, the participation effect works towards the policy preferences of those who prefer a larger welfare state.

Our paper is related to the political economy of interjurisdictional migration. Most notably in this respect is the contribution by Razin et al. (2002) who analyse the influence of migration on the size of the welfare state in a median voter setting. Immigration of low skilled workers changes the composition of voters and causes a "fiscal leakage effect" in their model. Both effects work in opposite directions with respect to the equilibrium level of redistributive taxes and transfers.

The paper is organized as follows: Section 2 presents some facts on the relationship between individual education levels and the mobility of citizens. Section 3 employs a simple cost-benefit calculus to show how political participation of citizens can be characterized from an economic viewpoint and how mobility can influence participation. Section 4 then applies this approach to the potential effects of mobility on political participation and the size of the welfare state. Section 5 extends the analysis, and Section 6 concludes.

\section{Mobility of the high-skilled}

Mobility and migration are persistent facts in most developed countries. The share of the foreign population in the U.S., for example, reached 10.4 percent in 2000 (OECD 2003), and for Europe the estimated number of people living in a country other than their country of origin is 21 million or 2.7 percent of the population (Wanner 2002). In some countries, for example Germany with 8.9 percent, the share of foreigners is considerably above this European average.

Survey evidence on the mobility of European citizens suggests that of those 38 percent who changed residence during a period of ten years, 21 percent moved to another region and 4.4 percent to another country within the EU (Eurobarometer 2001). Compared to the Europeans, citizens in the US are characterized by much higher levels of geographic mobility: they have about twice the mobility rate of EU citizens (European Commission 2001).

2 Theoretical support for this hypothesis can be derived from political economy models on redistributive tax-transfer-systems as in the tradition of Meltzer and Richard (1981). 
Some groups of people are more mobile than others. Specifically, there exists a positive relationship between mobility and the education level of citizens. 67 percent of all immigrants to the USA and 88 percent of those to the OECD possess a secondary education or higher (Adams 2003). With respect to international mobility, high-skilled citizens seem to be better suited to overcome linguistic and cultural barriers and also to be more welcome in recipient countries, presumably because of their contribution to the stock of human capital and to the welfare system. Recent changes in immigration laws in several countries therefore aim at facilitating the immigration of high-skilled workers (Mahroum 2001). At the same time, a higher mobility of the better educated is also observable at the national level: the labour market for the better educated seems to be less localized than the market for the less educated (see Ehrenberg and Smith 2003).

US Census data illustrates this positive relationship between education and mobility (Table 1). Between 2002 and 2003, 6.2 percent of the better educated (college or more) moved across the borders of their county of residence compared to 5.3 percent of the less educated. The pattern of a higher mobility among the better educated is visible across all age groups.

Table 1

USA: Mobility by educational attainment

March 2002 to March 2003 (total number in thousand)

\begin{tabular}{|l|rcc|}
\hline & Total number & \multicolumn{3}{c|}{$\begin{array}{c}\text { Movers across county borders } \\
\text { (percent of the total number) } \\
\text { High School and }\end{array}$} & $\begin{array}{c}\text { College and } \\
\text { more }\end{array}$ \\
\hline Age 25-29 & 18,721 & 10.2 & 13.3 \\
Age 30-34 & 20,521 & 7.6 & 8.5 \\
Age 35-44 & 44,073 & 5.5 & 5.8 \\
Age 45-64 & 67,635 & 3.2 & 3.8 \\
All & 150,950 & 5.3 & 6.2 \\
\hline
\end{tabular}

Source: U.S. Census Bureau (2004), own calculations.

Comparable results can be found with respect to interregional mobility within Germany. According to a study by Haas (2002), 52.4 percent of the workers with higher education who took up a new employment also have moved to 
another region compared to only 31.5 percent of those with professional training and 26.1 percent of those without training (Table 2). ${ }^{3}$

Table 2

Germany: Share of workers who take up a new employment in another region (as a percentage of all who take up a new employment)

\begin{tabular}{|lcccccc|}
\hline & \multicolumn{3}{c}{ Job to job switcher* } & \multicolumn{3}{c|}{$\begin{array}{c}\text { Change of location after } \\
\text { Unemployment }\end{array}$} \\
\hline & 1982 & 1990 & 1995 & 1982 & 1990 & 1995 \\
\hline $\begin{array}{l}\text { With profes- } \\
\text { sional training }\end{array}$ & 27.0 & 29.8 & 31.5 & 22.1 & 23.7 & 27.4 \\
$\begin{array}{l}\text { Without profes- } \\
\text { sional training }\end{array}$ & 20.1 & 22.8 & 26.1 & 16.3 & 17.3 & 19.1 \\
$\begin{array}{l}\text { Higher educa- } \\
\text { tion }\end{array}$ & 47.7 & 48.9 & 52.4 & 38.3 & 43.3 & 49.2 \\
$\begin{array}{l}\text { With general } \\
\text { qualification for } \\
\text { university } \\
\text { entrance (Germ.: } \\
\text { Abitur) }\end{array}$ & 43.0 & 44.2 & 47.1 & 36.2 & 41.1 & 44.8 \\
$\begin{array}{l}\text { Without general } \\
\text { qualification for } \\
\text { university } \\
\text { entrance }\end{array}$ & 24.2 & 27.2 & 29.4 & & & \\
\hline$*$ Direct change of workplace without previous unemployment. & \\
\hline
\end{tabular}

Source: Haas (2002).

Studies of emigration from Scandinavian countries show a similar pattern. Pirttilä's (2003) analysis of Finnish emigration and return migration in the 1990s reveals that individuals with higher academic education are 4.5 times more likely to emigrate than individuals with only secondary education. Pedersen at al. (2003) analyse emigration from Denmark, Norway and Sweden and find that emigration propensities in all three countries are clearly increasing in the level of education.

3 Similar patterns were found by Gregg et al. (2004) for inter-regional mobility rates in the UK, by Greenwood (1997) and Basker (2002) for the USA, Ledent (1990) for Canada and Carillo and Marselli (2003) for Italy. 


\section{Mobility and political participation}

Citizens have many options of participating in the political decision-making process. To name just a few of them: citizens can vote; they can write letters to political representatives or newspapers; they can join interest groups and political parties or donate money to these organizations; they can start or support political initiatives, referenda and the like; they can also stand as candidates for a political office themselves. These political activities differ with respect to the costs for the participating citizen in terms of time, effort and money. They also differ with respect to their influence on policy outcomes and to other potential benefits for the person engaging in the respective political activity. To take one extreme, the individual act of voting is associated with only small costs for the voter on the one hand, but on the other hand also with a small, if not negligible, expected influence on policy outcomes. ${ }^{4}$

In this paper we are interested in forms of political participation on the other side of the spectrum-political activities that come at significant costs and provide sizable potential benefits for the person undertaking the activity. Standing as a candidate for a political office or contributing financially to support a party or a political initiative are examples for such political activities. Participation of this kind bears some important parallels to an economic investment decision: citizens spend resources in the course of political participation that may yield benefits later on in the form of political influence or political rents. These benefits thus do not only derive from the citizen's political ideology, they may also result from non-political motives, for example, from obtaining access to social networks or gaining prestige from being a politically important person. Political investors compare the discounted sum of the benefits, the "political prize", with the participation costs. They participate in the political process only if the discounted payoff is high enough to cover the participation costs.

Consider now a representative citizen who has to decide whether to invest to a specific political activity in her jurisdiction. If she participates, she has to bear participation costs amounting to $c$. The discounted sum of all benefits that accrue from this kind of political participation is denoted by $R_{0}$. For simplicity, we assume that the citizen takes the costs and benefits as exogenously given. She then decides to participate only if $R_{0} \geq c$. For expositional reasons, we assume at this point that a politically active citizen receives the benefits of participation with certainty. One could easily extend this approach to include uncertainty concerning the individual success of political participation: a citizen, for

4 For an analysis of voter participation see, for example, Franzese (2000). 
example, may face a given probability of being successful in the political arena; $R_{0}$ then simply needs to be replaced by an appropriate expectation value.

In general, the terms $R_{0}$ and $c$ depend on a number of factors and individual characteristics. What is important for our analysis is their relationship with mobility. In this respect, we assume that a citizen receives benefits from her political activity in a given jurisdiction as long as she resides there. After relocation to another jurisdiction the benefits from a previous political activity cease to accrue. The payoff from political participation then can be expected to decline with the degree of the citizen's mobility.

To illustrate the relationship between mobility and the participation payoff, assume that in each period the citizen faces an exogenous probability $\theta$ of relocation to another jurisdiction. ${ }^{5}$ The parameter $\theta$ may denote, for example, the probability that the citizen is sent to another jurisdiction by her employer. By assuming an exogenous relocation probability our model abstracts from the citizen's option of voting with her feet. This option may provide an alternative way for mobile people to obtain their preferred policy. We expect, however, this factor to work in the same direction, i.e. towards a lower political participation of the mobile citizens.

Let the representative citizen decide in period 0 whether to participate in the political process or not. If she participates, she receives benefits $R$ from participation in each period as long as she resides in the jurisdiction. With an infinite time horizon and a discount rate of $r$ the expected payoff from participation is given by

$$
R_{0}^{m}=\frac{1-\theta}{r+\theta} R^{6}
$$

for a mobile citizen. For an immobile citizen the payoff is $R_{0}=R / r$. We see from the above equation that $R_{0}^{m}$ declines with an increase in the relocation probability $\theta$. The more mobile the citizen is, the lower is the expected discounted payoff and the less likely she invests the costs of participation $c$.

5 Glaeser et al. (2002) analyse the decision of individuals to invest in "social capital" in their jurisdiction of residence. They also use an exogenous relocation probability to model mobility.

6 With a relocation probability of $\theta$, the probability of residing in the jurisdiction in period 1 is $[1-\theta]$, and the benefit from participation in this period is $[1-\theta] R$; in period 2 the probability of staying in the jurisdiction is $[1-\theta]^{2}$, and the expected benefit is $[1-\theta]^{2} R$. This procedure can be extended to a any time horizon $T$. Summing up, discounting to period 0 , and taking the limit of $T$ approaching infinity then produces the equation in the text.. 


\section{Mobility and the size of the welfare state}

In this section we use the cost-benefit-calculus introduced above to discuss possible effects of personal mobility on the size of the welfare state. In Section 2 we have provided some strong evidence indicating that different groups of citizens are exposed to different degrees of interregional mobility. In particular, the degree of mobility increases with the education level. In Section 3 we have shown that mobile citizens may be less willing to participate in the local decision making process simply because they are inherently "footloose" and thus less interested in local political affairs.

Citizens differ in many respects: income, education, family size, age etc. All these factors influence their personal degree of mobility, but also their policy preferences. For our purposes, we focus on only one policy dimension, namely the size of the welfare state. We measure the size of the welfare state by the variable $x$, which is normalized to a value between 0 and 1 . Let $x$ denote, for example, the share of per capita government expenditures as a percentage of average income. Each citizen $i$ has an ideal policy position $x_{i}$, which denotes her most preferred size of the welfare state. We consider now political activities of citizen $i$ that are liable to move the policy outcome towards the most preferred policy $x_{i}$.

We start from a situation without mobility and first assume that neither the payoff from political participation $R_{0}$ nor its costs $c$ depend on the policy preferences of the citizen. ${ }^{7}$ In this case the individual cost-benefit calculus is independent of the policy position $x_{i}$ (Figure 1). Each citizen then has an incentive to participate if $R_{0}$ exceeds $c$ as portrayed in Figure 1.

If we introduce mobility in this setting, the payoff from participation declines due to the positive probability of leaving the community in the future. The $R_{0}$-curve in Figure 1 shifts downwards to a new curve $R_{0}^{m}$, which depicts the payoff from participation for more or less mobile citizens. As we have argued above, there are reasons to assume that mobility is higher for citizens who prefer a smaller size of the welfare state. The downward effect caused by mobility is thus stronger for low values of $x$ than for high values, and consequently $R_{0}^{m}$ increases in $x$.

7 In Section 5 we will discuss some implications of relaxing these assumptions. Specifically, we will assume that $R$ depends on the individual policy position $x$. A possible relationship between $c$ and $x$ can be analysed analogously. 
Figure 1

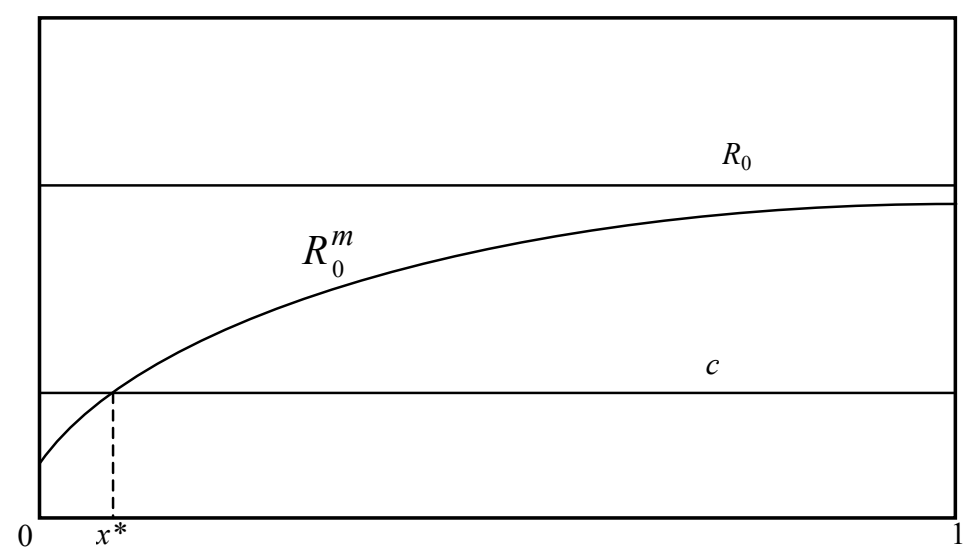

If the payoff curve $R_{0}^{m}$ intersects the cost line as shown in Figure 1, then all citizens who prefer a smaller size of the welfare state than $x^{*}$ exclude themselves from the political process. The payoff will not cover the costs of political participation for these citizens. Only those citizens participate whose ideal position is in the range between $x^{*}$ and 1 .

Up to now we have considered the cost-benefit calculus of a single citizen deciding about political participation. For a more general treatment of the participation issue we also have to take into account the strategic relationship between citizens with different policy preferences who decide whether to participate politically or not. This can be done by setting up a game-theoretic model of political participation and by deriving the equilibrium policy outcomes with and without mobility in this setting of strategic interaction.

In the following, we provide an illustrative example for such a model of strategic participation. This example is not meant to provide a realistic portrait of the complex process of endogenous welfare policy determination. Our objective is rather to demonstrate the potential effects of mobility on political participation in a simple and straightforward way. Consider the two citizens 1 and 2 with ideal positions $x_{1}=1 / 4$ and $x_{2}=3 / 4$, respectively. ${ }^{8}$ Both decide simultaneously and in a non-cooperative manner whether to become politically

8 We have chosen numbers instead of symbols for illustrative purposes. They are not crucial for the qualitative interpretations of the model. 
active by standing as a candidate in a "winner takes all"-election. ${ }^{9}$ The candidate who wins the election can determine the policy $x$ in the jurisdiction according to her own preferences..$^{10}$ If citizen 1 is the only candidate, she wins the election with certainty and can set $x=1 / 4$. If citizen 2 is the only candidate, the resulting policy outcome is $x=3 / 4$. For the case of both citizens running for election, each of them is elected with the same probability of 1/2.11 The expected policy outcome in this case is given by $E x=1 / 2$. The payoff of a candidate who is elected and who can determine the policy according to her own preferences is $R_{0}=1$. The payoff is 0 for a candidate who is not elected or for both citizens if none of them runs for election.

With these assumptions we can characterize the equilibrium policy outcome for the case without mobility. The equilibrium policy depends on the cost $c$ of running for election. For $c>1$, the cost exceeds the payoff $R_{0}=1$ for each citizen and consequently nobody stands for election and the policy outcome remains undetermined. For $1 / 2<c<1$ there are two possible equilibria, each with one citizen standing as a candidate and the other staying out. If citizen 1 enters as a candidate, citizen 2 does not have an incentive to enter as well and to challenge candidate 1 , since the expected payoff of entering for citizen 2 would be $1 / 2$. This is by assumption smaller than $c .{ }^{12}$ If citizen 2 stays out, however, citizen 1 has an incentive to enter and to become a candidate. Thus, an equilibrium exists with only citizen 1 entering. By the same reasoning, we can show that an additional one-candidate equilibrium exists with citizen 2 as a political candidate. If $c$ is even lower $(c<1 / 2)$, both citizens enter as political candidates and we obtain a two-candidate equilibrium. ${ }^{13}$ The expected policy in this equilibrium with two candidates is $1 / 2$.

If we introduce mobility in this setting, the payoff from participation declines for both citizens. Since the degree of mobility is higher for citizen 1 than for citizen 2, the payoff from participation $R_{0}^{m}$ is lower for candidate 1 than for

9 By assuming that only two citizens run as candidates, we sidestep questions concerning coalition formation.

10 This kind of model would also be suitable to analyse political participation in the form of a lobbying contest.

11 The assumption of the same election probabilities for both candidates simplifies our analysis and exposition as it makes the model perfectly symmetric. However, we could also think of other, more general, approaches in which election probabilities differ across candidates - for example, in a probabilistic voting set-up. Similar effects would also work in such a setting.

12 The expected payoff is given by the payoff of 1 times the probability of being elected. If both citizens are candidates, this probability is $1 / 2$.

13 For $c=1 / 2$ the two-candidate equilibrium and the two one-candidate equilibria co-exist. For $c=1$ the one-candidate equilibria and the equilibrium with no candidate entering co-exist. 
candidate 2. Figure 2 depicts possible combinations of $R_{0}^{m 1}$ and $R_{0}^{m 2}$. Since $R_{0}^{m 1}<R_{0}^{m 2}<1$ these payoff combinations are located above the $45^{\circ}$-line in the triangle $0 \mathrm{BE}$. The benchmark case without mobility is given by point $\mathrm{B}$. In Figure 2 we have assumed small costs of participation $(c<1 / 2)$, implying a 2-candidate equilibrium without mobility, the corresponding expected policy outcome amounting to $1 / 2$.

Figure 2

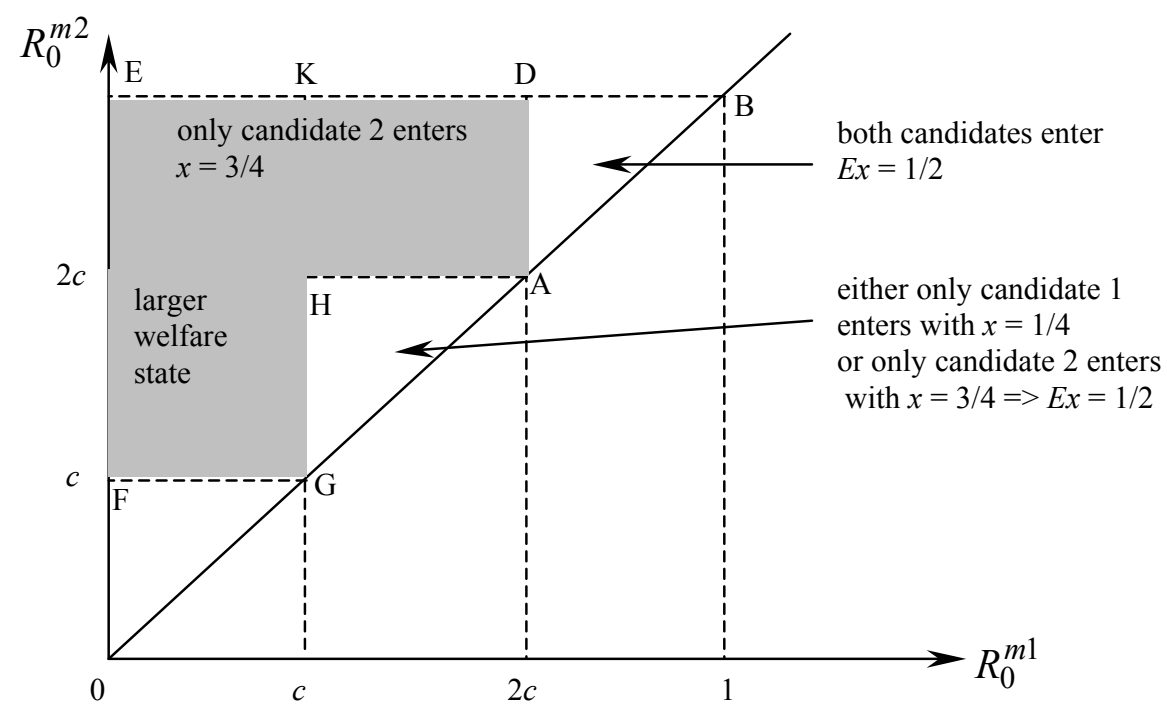

If the payoff for both candidates exceeds $2 c$, the two candidate equilibrium persists with mobility. This is the case in area ABD. If mobility causes a larger decline of payoffs, however, the election game no longer admits this twocandidate equilibrium. Area FGADE depicts all payoff combinations with $R_{0}^{m 2}>c$ and $R_{0}^{m 1}<2 c$. In this area a two-candidate equilibrium cannot exist: If candidate 2 enters, candidate 1 prefers to stay out of the competition. Area FGHADE covers all payoff-combinations in which only candidate 2 enters in equilibrium. This area includes pay-off combinations where $R_{0}^{m 2}>2 c$ and $c<R_{0}^{m 1}<2 c$. In this area (rectangle ADKH) entering is a dominant strategy 
for citizen 2, and citizen 1 does not enter if citizen 2 does. The area FGHADE also includes all payoff combinations with $R_{0}^{m 1}<c$ and $R_{0}^{m 2}>c$ (rectangle FGKE) where citizen 1 does not enter irrespectively of what citizen 2 does and citizen 2 enters. The size of the welfare state resulting from this one-candidate equilibrium with citizen 2 being the only candidate is $3 / 4$.

For the parameter combinations described by the triangle GAH $\left(c<R_{0}^{m 1}<2 c\right.$ and $R_{0}^{m 2}<2 c$ ) we obtain an additional one-candidate equilibrium with citizen 1 being the only candidate. We thus have two possible one-candidate equilibria in this area with either citizen 1 or citizen 2 entering as a candidate.

Finally, in the area described by the triangle 0GF both candidates abstain from political participation since the payoff in this area is smaller than the participation costs for both candidates; the policy outcome is therefore undetermined.

This simple example thus illustrates that mobility can give rise to an increase in the expected size of the welfare state for a large range of parameter values (area FGHADE). For these parameter constellations the two-candidate equilibrium, in which citizens on both sides of the political spectrum run for election, is replaced by a one-candidate equilibrium in which only a citizen who prefers a large welfare state has an incentive to enter the election.

In another paper (Lorz and Nastassine 2004) we employ a more complete model of political candidacy with interjurisdictional mobility. That model builds on the citizen-candidate approach developed by Osborne and Slivinski (1996) and Besley and Coate (1997). It assumes an entire continuum of citizens with different policy preferences who may stand as political candidates. As in the current paper, we assume that mobility differs between citizens with different policy preferences, such that relatively mobile citizens may be less willing to become candidates in local elections than citizens with a lower degree of mobility. In such a setting, equilibria with one, two or more than two candidates can emerge. Comparable to the two-citizen example presented here, mobility causes a policy shift towards the preferences of the less mobile citizens for certain parameter values.

\section{Extensions}

In the previous sections we have assumed that without mobility all citizens face the same payoffs and fixed costs of political participation - independently of their political position. In contrast to this assumption, some scholars point out that better educated citizens may have higher incentives to become active in the political arena than less educated citizens. Brady (2003), for example, 
develops a political contribution model in which the marginal returns from political participation are higher for citizens who expect a higher income. ${ }^{14}$ The government imposes a proportional tax on high incomes and distributes the tax revenues between the income groups in proportion to political contributions received. If the rich are less numerous than the poor, individuals with a high income pay higher political contributions.

Translating this idea into our cost-benefit diagram, the $R_{0}$-curve, which depicts payoffs from political participation of immobile citizens, is no longer flat but decreasing in $x$ : the political prize is higher for citizens who expect a higher income and therefore prefer a smaller size of the welfare state (see Figure 3). Those citizens who prefer a very large size of the welfare state may not find it worthwhile to become politically active in the benchmark case without mobility. For these citizens the discounted benefits do not cover the costs of participation.

Introducing mobility in such a setting again reduces the payoff of political participation for all citizens, and the $R_{0}$-curve is replaced by the $R_{0}^{m}$-curve. Notice, that the new $R_{0}^{m}$-curve is not necessarily upward sloping anymore for all $x$. Instead, Figure 3 depicts a $R_{0}^{m}$-curve which is upward sloping for low values of $x$ and downward sloping for high $x .{ }^{15}$ For a citizen who prefers a very small size of the welfare state (below $x_{1}{ }^{*}$ ) the payoff from participation is lower than the costs and the citizen refrains from participating. This is the standard mobility effect already analysed in Section 4 . However, mobility may now also influence participation on the other side of the political spectrum: since high- $x$ citizens have low benefits to begin with, mobility - even though it does not affect them as much as the low- $x$ citizens - may well erode the benefits to such an extent that participation becomes unattractive (see Figure 3). Mobility then cuts off participants at both ends of the policy spectrum and in this sense can give rise to a convergence towards centrist policies.

As a second extension we replace our simplifying assumption that citizens can only choose between taking or leaving some kind of political activity. Instead, we consider a more general model in which the citizens can choose the degree of individual political involvement. For this purpose the fixed costs of participation $c$ are replaced by the function $c(e)$, where $e$ denotes the effort invested in the political activity. We assume a convex cost function $\left(c^{\prime}(e) \geq 0\right.$, $\left.c^{\prime \prime}(e)>0\right)$ with $c(0)=c^{\prime}(0)=0$. The political benefit $R$ now also depends on $e$,

\footnotetext{
14 For empirical evidence concerning the influence of education on political participation, see, for example, Dee (2003) or Milligan et al. (2003).

15 The $R_{0}^{m}$-curve may also be upward or downward sloping over the entire range of $x$.
} 
with $R^{\prime}(e)>0$ and $R^{\prime \prime}(e) \leq 0$. The payoff from participation $R_{0}^{m}$ is then also a function of $e$ and $\theta: R_{0}^{m}=R_{0}^{m}(e, \theta)$, with $\partial R_{0}^{m} / \partial e>0, \partial R_{0}^{m} / \partial \theta<0$, $\partial^{2} R_{0}^{m} / \partial e \partial \theta<0$ and $\partial^{2} R_{0}^{m} / \partial e^{2} \leq 0$. The marginal payoff from an increase in $e$ thus declines in the relocation probability $\theta$.

\section{Figure 3}

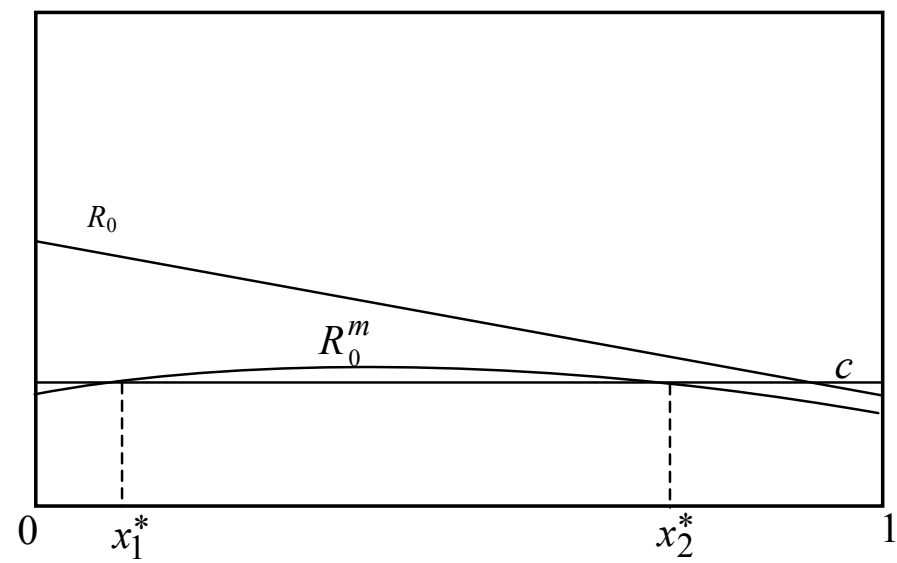

The utility maximizing effort level $e^{*}$ is implicitly determined by the firstorder condition $\partial R_{0}^{m} / \partial e-\partial c / \partial e=0$. Without mobility $\theta=0$, and the effort level is independent of the citizen's policy position. For mobile citizens the optimal effort level varies according to

$$
\frac{d e^{*}}{d \theta}=-\frac{\partial^{2} R_{0}^{m} / \partial e \partial \theta}{\partial^{2} R_{0}^{m} / \partial e^{2}-\partial^{2} c / \partial e^{2}}<0 .
$$

The higher the relocation probability $\theta$, the lower is the effort level $e^{*}$. This is in line with the result derived in section 3: the level of effort invested in the political process declines with the degree of individual mobility.

\section{Concluding remarks}

Personal mobility is the subject of controversial discussions since it may have severe political, economic and social consequences. Many of these mobility- 
induced effects have received due attention in the economic literature. In this paper we analyse an aspect that has been neglected so far, namely the influence of mobility on political participation and the potential implications of this effect for the size of the welfare state. We have argued that mobility of citizens may influence policy outcomes if citizens who differ with respect to their preferred policy are also exposed to different degrees of interjurisdictional mobility. Specifically, empirical evidence suggests that the well educated citizens, who in general prefer a smaller size of the welfare state, are also more mobile than the low-skilled citizens. Mobility may then reduce the most mobile citizens' willingness to participate in the political process since they have a relatively low attachment to their jurisdiction.

Focusing on the participation effect of mobility, we have neglected all other potential consequences of mobility for the size of the welfare state. We have followed this strategy for reasons of analytical convenience and not because we think that the participation effect dominates the other channels of influence. The most notable in this respect is tax competition for mobile factors of production. The standard result derived from a benchmark tax competition model is a "race to the bottom" as described in the introduction. Generalizing the basic tax competition model adds, however, some important qualifications. In a setting of asymmetric country sizes, for example, tax exportation motives may in some countries give rise to an increase in redistributive taxation (see Cremer et al. 1996, or Cremer and Pestieau 2003). A promising field for future research would be to analyse the participation effect discussed in this paper in a tax competition model to incorporate another important facet in the discussion of tax competition.

\section{References}

Adams, R.H., jr. (2003), "International Migration, Remittances and the Brain Drain", World Bank Policy Research Working Paper no. 3069.

Basker, E. (2002), "Education, Job Search and Migration", University of Missouri-Columbia Working Paper no. 02-16.

Besley, T. and S. Coate (1997), "An Economic Model of Representative Democracy”, Quarterly Journal of Economics 112, 85-114.

Brady, H.E. (2003), "An Analytical Perspective on Participatory Inequality and Income Inequality", paper for the Russel Sage Foundation Project on the "Social Dimensions of Inequality", University of California, Berkeley. 
Brown, C.C. and W.E. Oates (1987), "Assistance to the Poor in a Federal System", Journal of Public Economics 32, 307-330.

Brueckner, J.K. (2000), "Welfare Reform and the Race to the Bottom: Theory and Evidence", Southern Economic Journal 66, 505-525.

Carillo, M.R. and R. Marselli (2003), "Internal Migration and Search Costs in Italy: the Role of the Regional Production System", Working Paper.

Cremer, H., V. Fourgeaud, M. Leite-Monteiro, M. Marchand and P. Pestieau (1996), "Mobility and Redistribution: A Survey", Public Finance/Finances Publique 51, 325-352.

Cremer, H. and P. Pestieau (2003), "Factor Mobility and Redistribution: A Survey", Working Paper.

Dee, T.S. (2003), “Are there Civic Returns to Education?”, NBER Working Paper no. 9588.

Ehrenberg, R.G. and R.S. Smith (2003), Modern Labor Economics: Theory and Public Policy, Addison Wesley, 8th Edition, Boston.

Eurobarometer (2001), The Social Situation in the European Union, Report no. 54.2, European Opinion Research Group, Brussels.

European Commission (2001), High Level Task Force on Skills and Mobility Final Report, Brussels

Franzese, R.J., jr. (2000), "Political Participation, Income Distribution and Public Transfers in Developed Democracies", Working Paper.

Glaeser, E.L., D. Laibson and B. Sacerdote (2002), “An Economic Approach to Social Capital”, Economic Journal 112, F437-F458.

Greenwood, M.J. (1997), "Internal Migration in Developed Countries", in M.R. Rosenzweig and O. Stark (eds.), Handbook of Population and Family Economics, Volume 1B, Elsevier Science, Amsterdam.

Gregg, P., S. Machin and A. Manning (2004), "Mobility and Joblessness", in D. Card, R. Blundell, and R. B. Freeman (eds.), Seeking a Premier Economy: The Economic Effects of British Economic Reforms 1980-2000, NBER Comparative Labor Market Series, University of Chicago Press.

Haas, A. (2002), "Regionale Mobilität gestiegen", IAB Kurzbericht, German Institute for Labour Market Research, Nuremberg.

Ledent, J (1990), "Canada", in C.B. Nam, W.J. Serow, and D.F. Sly (eds.), International Handbook on Internal Migration, Greenwood Press, New York. 
Lorz, O. and S. Nastassine (2004), Citizen-Candidate Mobility and Endogenous Local Policy, Working Paper.

Mahroum, S. (2001), "Europe and the Immigration of Highly Skilled Labour", International Migration 39 (Special Issue 1), 27-43.

Meltzer, A.H. and S.F. Richard (1981), "A Rational Theory of the Size of the Government”, Journal of Political Economy 89, 914-927.

Milligan, K., E. Moretti and P. Oreopoulos (2003). "Does Education Improve Citizenship? Evidence for the U.S. and the U.K." NBER Working Paper no. 9584.

Oates, W.E. (1972), Fiscal Federalism, Harcourt Brace Jovanovich, New York.

OECD (2003), Trends in International Migration: Continuous Reporting System on Migration, SOPEMI Annual Report 2002 Edition, Paris.

Osborne, M.J. and A. Slivinski (1996), "A Model of Political Competition with Citizen Candidates", Quarterly Journal of Economics 111, 65-96.

Pedersen, P., M. Røed and L. Schröder (2003), "Emigration from the Scandinavian Welfare States", in T. Andersen and P. Molander (eds.), Alternatives for Welfare Policy, Cambridge University Press, Cambridge.

Pirttilä, J. (2003), "Is International Labour Mobility a Threat to the Welfare State? Evidence from Finland in the 1990s", Paper presented at the CESifo Economic Studies Conference "Migration and the Welfare State".

Razin, A., E. Sadka and P. Swagel (2002), "Tax Burden and Migration: A Political Economy Theory and Evidence", Journal of Public Economics 85, 167-190.

Sinn, H.-W. (1997), "The Selection Principle and Market Failure in Systems Competition", Journal of Public Economics 66, 247-274.

U.S. Census Bureau (2002). Current Population Survey, 2003 Annual Social and Economic Supplement, Washington D.C.

Wanner, P. (2002), Migration Trends in Europe, European Population Papers Series No. 7, Council of Europe, Strasbourg.

Wildasin, D.E. (1991), "Income Redistribution in a Common Labor Market", American Economic Review 81: 757-774. 